\title{
Osseointegration Aspects of Implants at the Bone Reconstruction Site by a Novel Porous Titanium Scaffold
}

\author{
Kazuya Doi ${ }^{1}$, Reiko Kobatake ${ }^{1}$, Yusuke Makihara ${ }^{1}$, Yoshifumi Oki ${ }^{1}$, Hanako Umehara ${ }^{1}$, Takayasu \\ Kubo $^{1}$, Kazuhiro Tsuga ${ }^{1}$
}

${ }^{1}$ Department of Advanced Prosthodontics, Hiroshima University Graduate School of Biomedical and Health Sciences, Hiroshima, Japan.

\author{
Corresponding Author: \\ Kazuya Doi \\ Department of Advanced Prosthodontics \\ Hiroshima University Graduate School of Biomedical and Health Sciences \\ 1-2-3, Kasumi, Minami-ku, Hiroshima 734-8553 \\ Japan \\ Phone: +81 822575677 \\ Fax: +81 822575679 \\ E-mail: kazuya17@hiroshima-u.ac.jp
}

\begin{abstract}
Objectives: Porous titanium is used for the reconstruction of large bone defects due to its excellent mechanical strength. The quality of osseointegration of implants placed in bone reconstructed with porous titanium is unknown. The purpose of this in vivo study was to evaluate the osseointegration of implants at sites reconstructed using porous titanium.

Material and Methods: Hollow porous titanium (Ti) (outer-diameter $6 \mathrm{~mm}$, inner-diameter $2 \mathrm{~mm}$, length $4 \mathrm{~mm}, 85 \%$ porosity) and similar-sized porous hydroxyapatite (porous HA: 75\% porosity) samples were prepared and implanted in 6 New Zealand white rabbit femurs. Four weeks later, an implant bed was created to receive a Ti implant (diameter $2 \mathrm{~mm}$, length $4 \mathrm{~mm}$ ). An implant placed at a pristine bone site served as the control. Four weeks later, histological and histomorphometric evaluations of the test and control sites were conducted.

Results: Osseointegration was observed in all groups. There was no significant difference in the bone formation ratio and bone-implant contact (BIC) ratio across all groups for the whole area. At the cancellous bone area of the bone defect, superior bone formation ratio and $\mathrm{BIC}$ ratio were observed with porous Ti and porous HA compared to the control (bone formation ratio: control 1.8 [SD 3]\%, HA 23 [SD 3]\%, Ti 23.6 [SD 5]\%; BIC ratio: control 5.4 [SD 5.3]\%, HA 28.9 [SD 10.7]\%, Ti 41.6 [SD 14]\%). Porous Ti demonstrated good osteoconduction and osseointegration abilities, similar to porous HA.

Conclusions: To our knowledge, this is the first report of implant treatment after preliminary bone reconstruction using a titanium biomaterial. Porous titanium is a suitable material for bone reconstruction before implant treatment in load-bearing areas that allow subsequent prosthetic treatment.
\end{abstract}

Keywords: biocompatible material; dental implants; dental implantation; oseointegration; titanium.

\author{
Accepted for publication: 11 August 2021 \\ To cite this article: \\ Doi K, Kobatake R, Makihara Y, Oki Y, Umehara H, Kubo T, Tsuga K. \\ Osseointegration Aspects of Implants at the Bone Reconstruction Site by a Novel Porous Titanium Scaffold \\ J Oral Maxillofac Res 2021;12(3):e4 \\ URL: http://www.ejomr.org/JOMR/archives/2021/3/e4/v12n3e4.pdf \\ doi: $10.5037 /$ jomr.2021.12304
}




\section{INTRODUCTION}

Successful predictable implant therapy depends on the bone quantity and quality at the placement site [1]. Large bone defects due to injury or tumours can complicate implant rehabilitation. In such situations, implant treatment is performed after bone reconstruction using autologous or artificial bone grafts $[2,3]$. Autografts do not carry a risk of inflammation and have excellent osteoconduction properties; therefore, they are the gold standard for bone graft materials. However, there are several problems with the limited amount of autologous bone being harvested $[\underline{4}, \underline{5}]$. Hydroxyapatite (HA), an artificial bone substitute, has been used as a graft material due to its excellent biocompatibility and osteoconduction properties. Furthermore, HA, with its porous structure, facilitates implant placement after reconstruction due to the ingrowth of bone within the grafted material [6-8].

Our previous studies $[9,10]$ demonstrated osseointegration of implants after the reconstruction of the preliminary bone site with interconnected porous HA. Despite the high biocompatibility and excellent osteoconduction ability of HA, it is not suitable for the reconstruction of large-size bone defects due to its insufficient mechanical strength. Therefore, novel materials with excellent mechanical strengths and osteoconduction properties are required. Currently, autologous bone or titanium (Ti) plates are used as reconstruction materials for large defects. The Ti plate is quite popular as it does not require invasive bone harvesting procedures; however, this treatment does not lead to bone formation at the defect site. On the other hand, porous $\mathrm{Ti}$ is a popular alternative in the field of orthopaedics and dentistry due to its biocompatibility and ability to avoid stress-shielding compared to bulk Ti $[11,12]$. Our previous study showed that reconstruction with porous $\mathrm{Ti}$ allows defect sites to be filled with bone due to its interconnected porous structure and osteoconduction properties [13]. Porous Ti, fabricated by the resin-impregnated substitution technique, has a three-dimensional structure where each pore is interconnected. Moreover, it has superior mechanical strength as compared to porous HA. Therefore, implant placement can be used to establish osseointegration in the preliminary bone-reconstructed site using porous $\mathrm{Ti}$. To the best of our knowledge, there are no reports on the implant placement at the preliminary bone-reconstructed site using $\mathrm{Ti}$ biomaterials.

The purpose of this in vivo study was to evaluate the osseointegration of implants at sites reconstructed using porous titanium.

\section{MATERIAL AND METHODS Materials}

Hollow pure Ti samples with an $85 \%$ interconnected porous structure (outer diameter $6 \mathrm{~mm}$, inner diameter $2 \mathrm{~mm}$, length $4 \mathrm{~mm}$, and pore size $300 \mu \mathrm{m}$ ) were fabricated using the resin-impregnated Ti substitution method and used in this study (Figure 1) [13]. The inner hole was made with high-speed drilling with irrigation. Similar-sized porous HA samples (porosity $75 \%, 150 \mu \mathrm{m}$ pore size, NEOBONE ${ }^{\circledR}$, Aimedic MMT Co., Ltd. Materials, Tokyo, Japan) were also prepared. An inner hole was set at the central portion of the porous material. A custom-fabricated pure Ti implant of diameter $2 \mathrm{~mm}$ and height $4 \mathrm{~mm}$ (Grade 3 - Nishimura Metal Co., Ltd.; Fukui, Japan) was also used (Figure 2). The implant had no threads, and the surface was acid treated by $48 \% \mathrm{H}_{2} \mathrm{SO}_{4}\left(60{ }^{\circ} \mathrm{C}, 1 \mathrm{~h}\right)$.

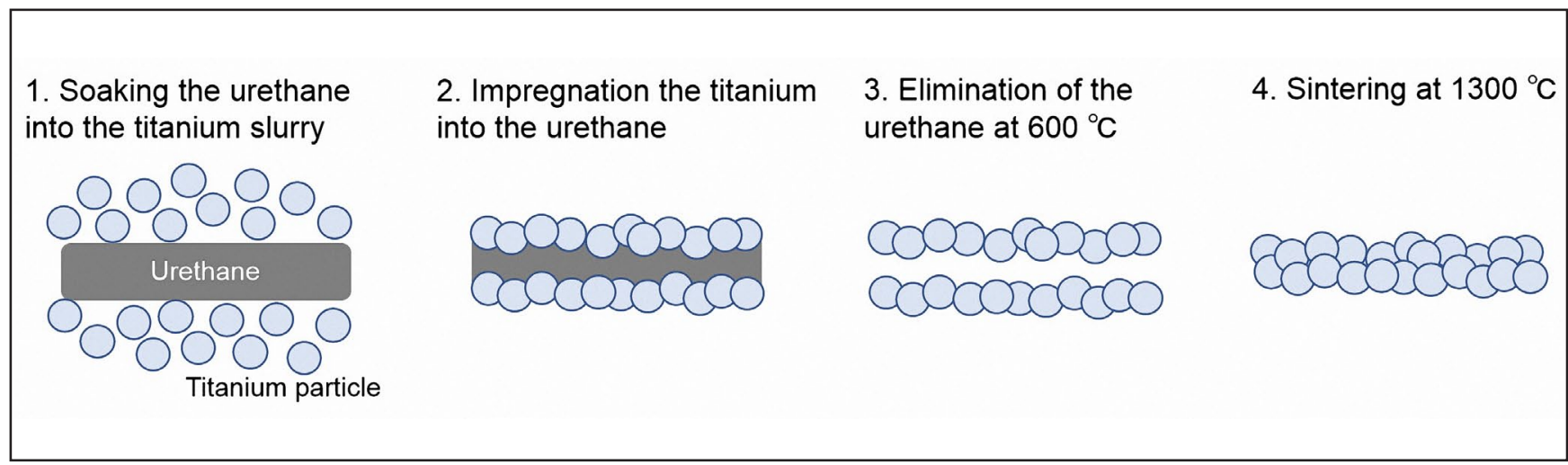

Figure 1. Schematic representation of the resin-impregnated titanium (Ti) substitution fabrication technique.

The urethane base material was immersed in a Ti slurry to adsorb Ti particles on the surface. After the urethane was removed by heat treatment at $600{ }^{\circ} \mathrm{C}$, sintering at $1300{ }^{\circ} \mathrm{C}$ was performed, whereby the Ti particles were sintered and bonded. Using this process, a porous Ti body with a structure similar to the base urethane form was produced [11]. 


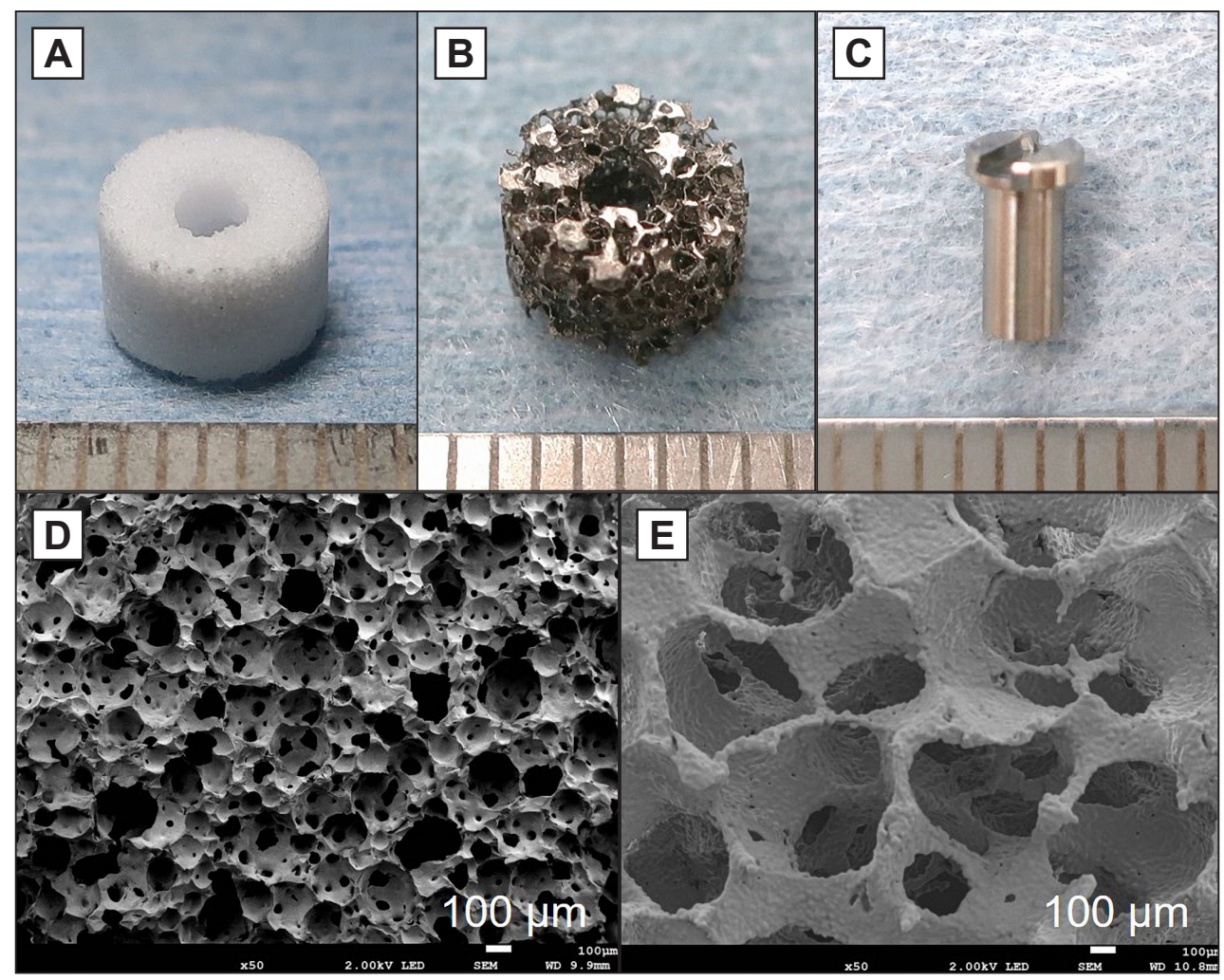

Figure 2. Materials: $\mathrm{A}=$ porous hydroxyapatite $(\mathrm{HA}) ; \mathrm{B}=$ porous $\mathrm{Ti} ; \mathrm{C}=$ custom titanium implant; $\mathrm{D}=$ porous HA surface; $\mathrm{E}=$ porous Ti surface. Porous bone reconstruction materials are hollow (outer diameter $6 \mathrm{~mm}$; inner diameter $2 \mathrm{~mm}$; length $4 \mathrm{~mm}$ ). The central inner hole was sized to fit the custom-fabricated pure titanium implant (diameter: $2 \mathrm{~mm}$, height: $4 \mathrm{~mm}$ ). Three-dimensional interconnected porous structures were detected in both the porous samples and the pore sizes were $150 \mu \mathrm{m}$ in porous HA and $300 \mu \mathrm{m}$ in porous Ti (original magnification x50 in SEM images).

\section{Evaluation of the material structure}

The porous Ti and HA was evaluated. All samples were sputtered with platinum-palladium to make the surface conductive, set on the sample stage using carbonate adhesive tape, and examined with scanning electron microscopy (JSM-7200F; JEOL Ltd., Tokyo, Japan) at an original magnification $\times 100$.

\section{In vivo study}

The study was approved by the Research Facilities Committee for Laboratory Animal Science, Hiroshima University School of Medicine (approval no. A16-3). The animal procedure is shown in Figure 3.

Six New Zealand white rabbits (male, 17 weeks old, and weight of 3 to $3.5 \mathrm{~kg}$ ) were used. Prior to any experiment, animals were quarantined in individual cages for a week. All animal experiments were conducted in compliance with the rules of animal experiment in Hiroshima University. Animals were housed in a temperature-, humidity-, and air renewalcontrolled room and accommodated under a $12 \mathrm{~h}$ light-dark cycle. Animals were fed standard dried diet and water ad libitum.

The surgical procedures were performed under general anaesthesia with sodium pentobarbital (10 $\mathrm{mg} / \mathrm{kg}$ ) and local infiltration anaesthesia with $2 \%$ lidocaine with 1 : 80,000 noradrenaline. Muscle and periosteal flaps were made on the left and right femurs, and a bone defect (diameter: $6 \mathrm{~mm}$, length: $4 \mathrm{~mm}$ ) was made using a trephine $1200 \mathrm{rpm}$ with irrigation. Each porous sample was placed in the bone defect. Four weeks later, in a similar operation, the placed porous samples were exposed. The implant was placed at the central portion of the porous sample: the hole was made using a $2 \mathrm{~mm}$ diameter pilot drill $1200 \mathrm{rpm}$ with irrigation (HA group, Ti group). At this stage, implants were placed in the existing bone to act as the control. The implants were fixed by press-fit implantation and tight sutures.

Four weeks after implantation (i.e., 8 weeks after the first operation), the rabbits were anaesthetized and perfused with $10 \%$ neutral formalin through the aorta. Femurs were harvested and fixed in $10 \%$ neutral formalin for 1 week.

\section{Histological evaluation}

Tissue blocks including the grafted samples and implants were cut, dehydrated with ethanol, and then embedded in resin (Technovit ${ }^{\circledR} 7200$ VLC - Kulzer, 


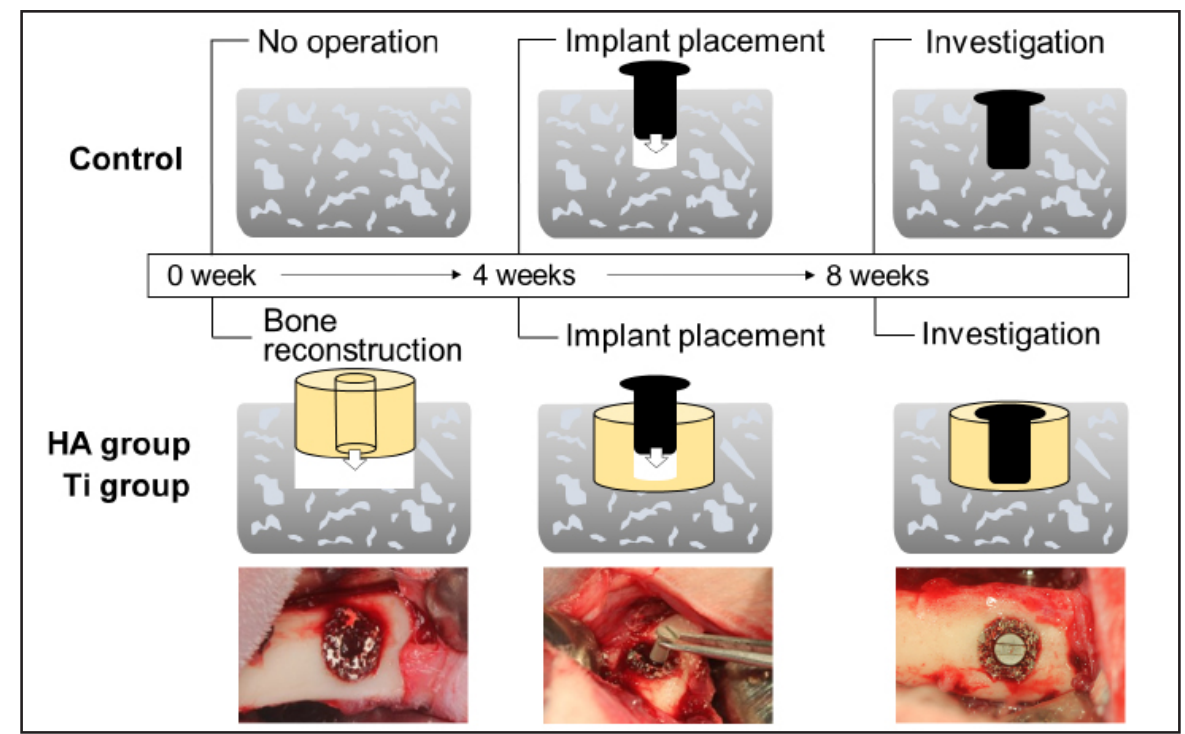

Figure 3. Operation protocol. Porous titanium (Ti) and porous hydroxyapatite were placed in the bone defects. Four weeks after placement, the Ti implant was placed at the central hollow portion of the bone reconstruction material. In the control group, the implant was placed on the existing bone. Further, 4 weeks later, the implantation outcome was assessed.

Wehrheim, Germany). The resin blocks were cut at the centre of the implant and ground to a thickness of approximately $60 \mu \mathrm{m}$. The specimens were stained with toluidine blue, and the images exhibiting bone regeneration were digitized.

\section{Histomorphometric evaluation}

The specimens were histomorphometrically analysed using the Image ${ }^{\circledR}$ software (Fiji distribution; National Institute of Health, Bethesda, Maryland, USA).

The region of interest was set as a $1 \mathrm{~mm}$ (width) $\times 4 \mathrm{~mm}$ (length) area along the implant surface and divided into the upper portion (cortical bone area [BA]) and the lower portion (cancellous BA) (Figure 4). The newly formed BA was calculated as the ratio of the bone tissue area to the total tissue area in the pore. The bone-implant contact (BIC) was measured as the ratio of BIC length to the implant length.

\section{Statistical analysis}

Statistical analysis was conducted using the one-way ANOVA Kruskal-Wallis test followed by Tukey's honestly significant difference test for multiple comparisons $(n=4)$. Statistical significance was set at $\mathrm{P}<0.05$. Parametric data were expressed as mean and standard deviation (M [SD]).

\section{RESULTS \\ Material structure}

Both porous HA and porous Ti had three-dimensional

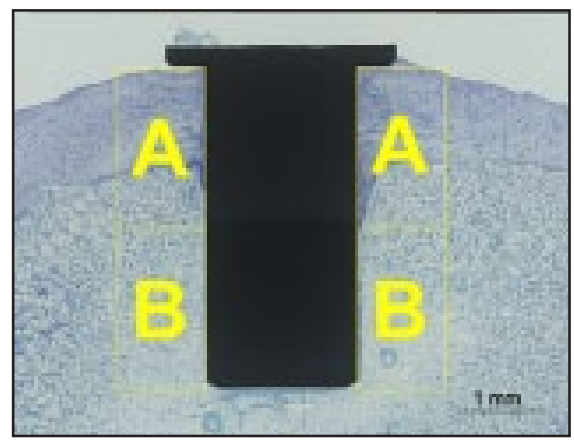

Figure 4. Region of interest: $\mathrm{A}=$ cortical bone area; $\mathrm{B}=$ cancellous bone area.

The region of interest was defined as an area of $4 \mathrm{~mm}$ length $\times 1$ $\mathrm{mm}$ width, and was evaluated by dividing it into an upper portion (cortical bone area) and a lower portion (cancellous bone area) ( $2 \mathrm{~mm}$ length $\times 1 \mathrm{~mm}$ width each).

interconnected porous structures. The pore sizes were $150 \mu \mathrm{m}$ in porous $\mathrm{HA}$ and $300 \mu \mathrm{m}$ in porous Ti (Figure $2 \mathrm{D}$, E, original magnification $\mathrm{x} 50$ ).

\section{General characteristics}

None of the implants showed mobility or loss. No inflammation was observed in the operation site.

\section{Histological observation}

The Ti implant exhibited osseointegration in the control group. The bone formation was limited to half of the upper portion, and the lower portion exhibited almost no bone formation or osseointegration (Figure 5).

In porous HA and porous Ti samples, bone formation into the material was observed. Bone formation and 


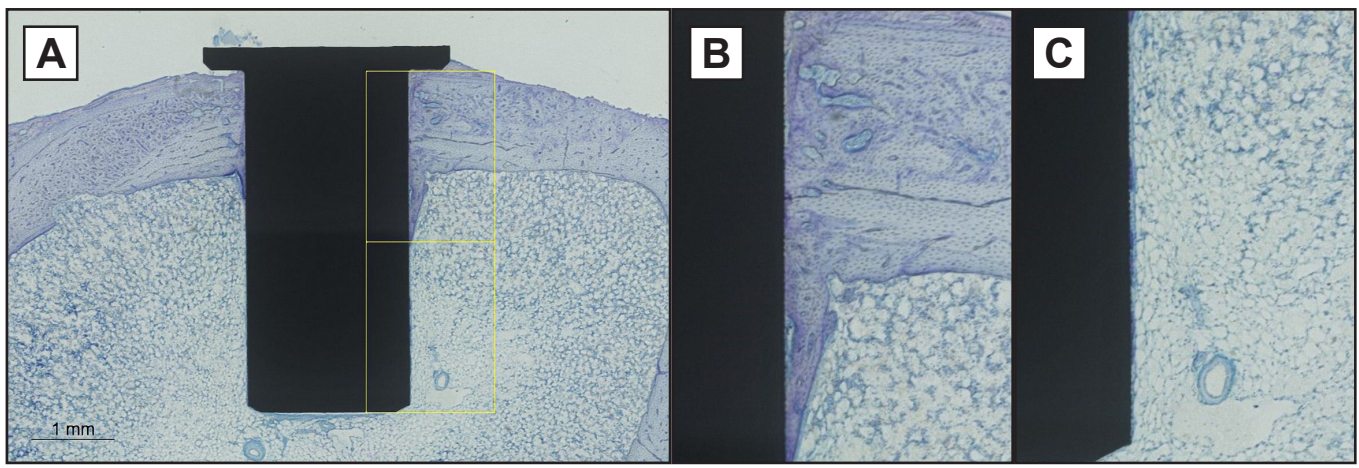

Figure 5. Histology of control. An implant in the existing bone: $\mathrm{A}=$ whole area; $\mathrm{B}=$ cortical bone area; $\mathrm{C}=$ cancellous bone area. Osseointegration was observed in the cortical bone area and there was less bone formation in the cancellous bone area.

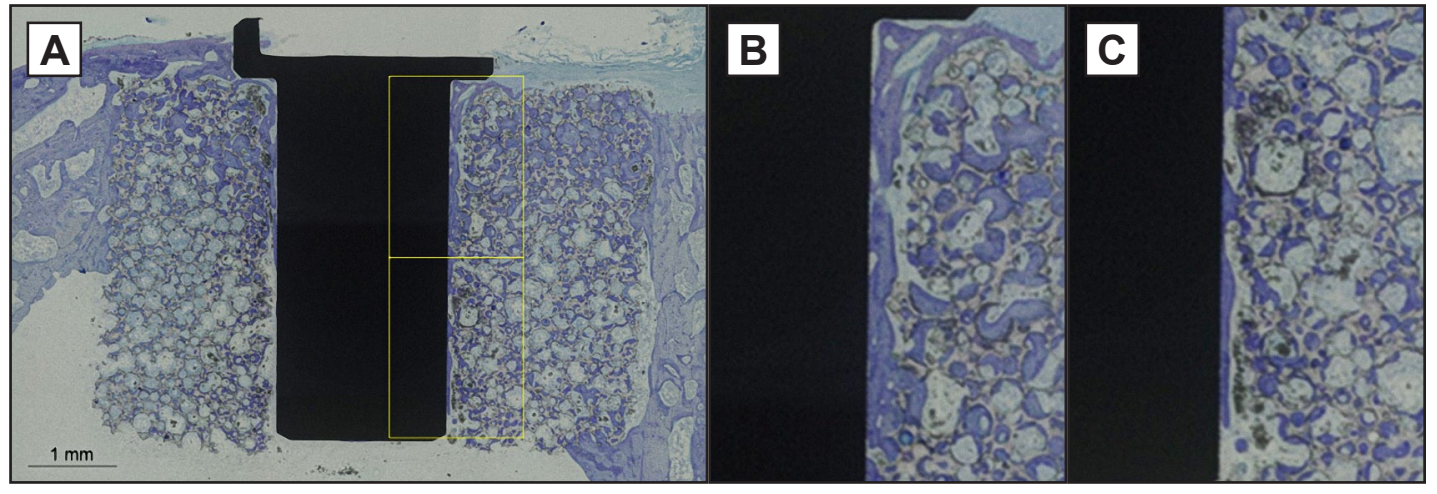

Figure 6. Histology of porous hydroxyapatite (HA). An implant in the bone reconstructed site by porous HA: A= whole area; B = cortical bone area; $\mathrm{C}=$ cancellous bone area.

Bone formation from the pristine bone was observed at the bone-porous HA interface.

Both in the cortical and cancellous bone areas, new bone formation and osseointegration were observed.

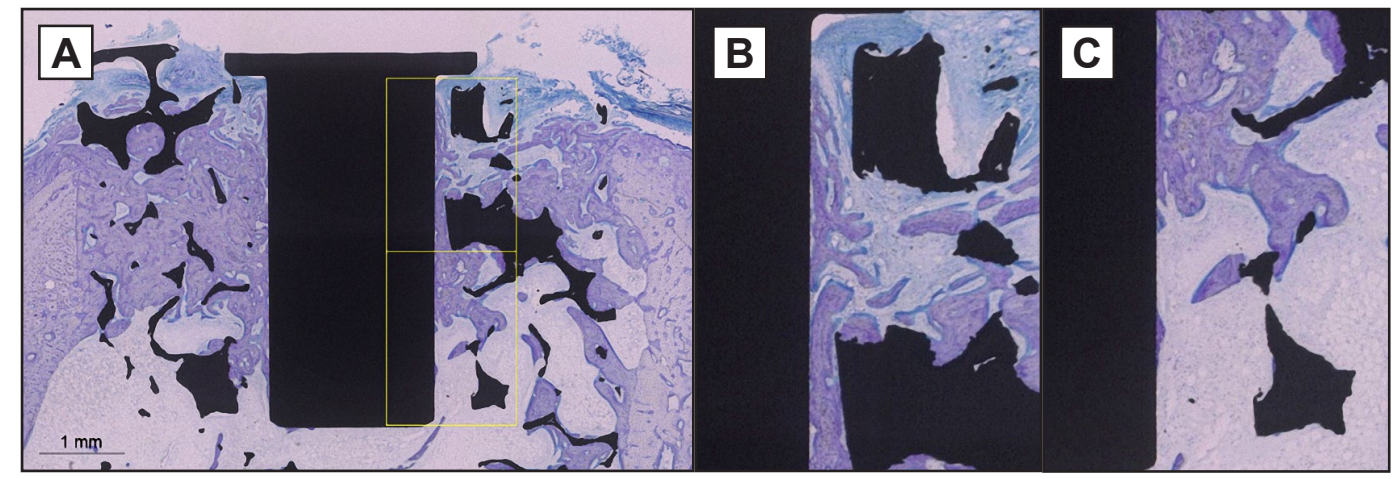

Figure 7. Histology of porous titanium (Ti). An implant in the bone reconstructed site by porous hydroxyapatite: $\mathrm{A}=$ whole area; $\mathrm{B}=$ cortical bone area; $\mathrm{C}=$ cancellous bone area.

At the bone-porous Ti marginal area, bone formation from the pristine bone was observed.

Both in the cortical and the cancellous bone areas, new bone formation and osseointegration were observed.

osseointegration were achieved along the porous materials of the bone scaffolds, both in the upper and lower portions (Figures 6 and 7).

\section{Histomorphometric analysis}

No significant differences were observed between the groups for $\mathrm{BA}$ and $\mathrm{BIC}$ of the total area $\mathrm{BA}$ : control 34.9 [7] $\%$, HA 34.9 [5.6]\%, Ti 42.5 [3.5]\%; BIC: control $38.1[6.6] \%$, HA 43 [9.2]\%, Ti 49.3 [9.2]\%).
In the HA group, BA in the upper portion (46.6 [8]\%) was lower compared to that in the control group (67.9 $[12.2] \%)$. At the lower portion, the $\mathrm{Ti}(23.6[5] \%)$ and HA groups $(23[3] \%)$ had increased bone formation compared to the control (1.8 [3]\%) (Figure 8). The $\mathrm{BIC}$ in the upper portion demonstrated no significant differences among the groups; however, in the lower portion, the Ti $(41.6[14] \%)$ and HA groups (28.9 $[10.7] \%)$ had higher BIC values than the control group (5.4 [5.3]\%) (Figure 9). 


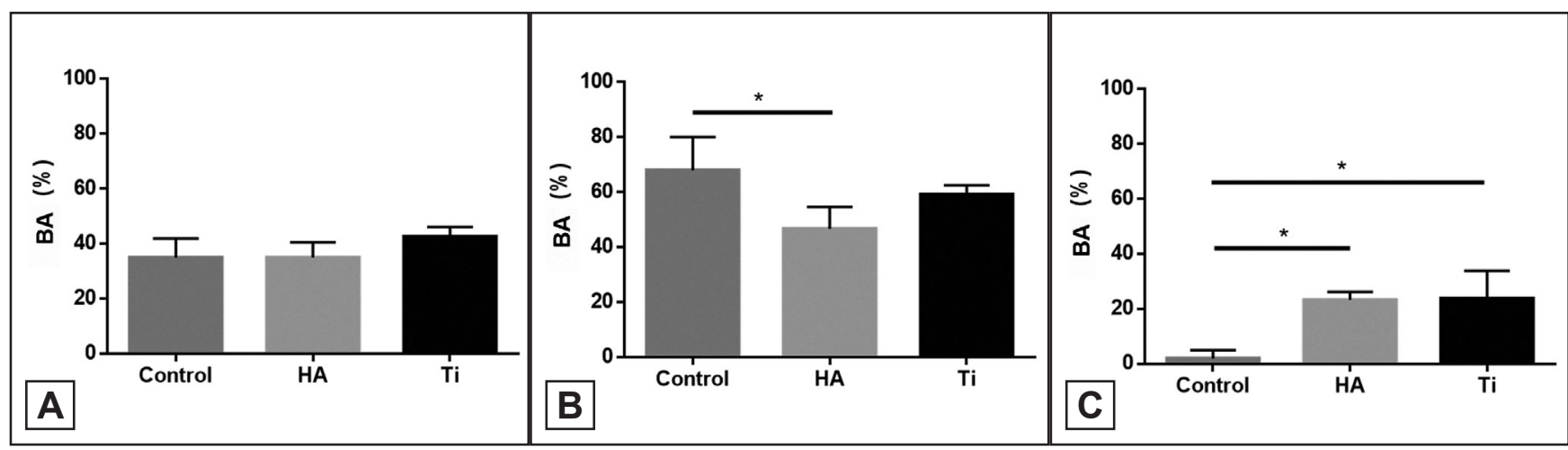

Figure 8. Bone area: $\mathrm{A}=$ whole area; $\mathrm{B}=$ cortical bone area; $\mathrm{C}=$ cancellous bone area.

There was no significant difference in the whole area $(\mathrm{P}=0.25$, Kruskal-Wallis test). In the cortical bone area, the titanium (Ti) group had no significant differences. In the cancellous bone area, hydroxyapatite and Ti group were higher than the control group. $* \mathrm{P}<0.05$.

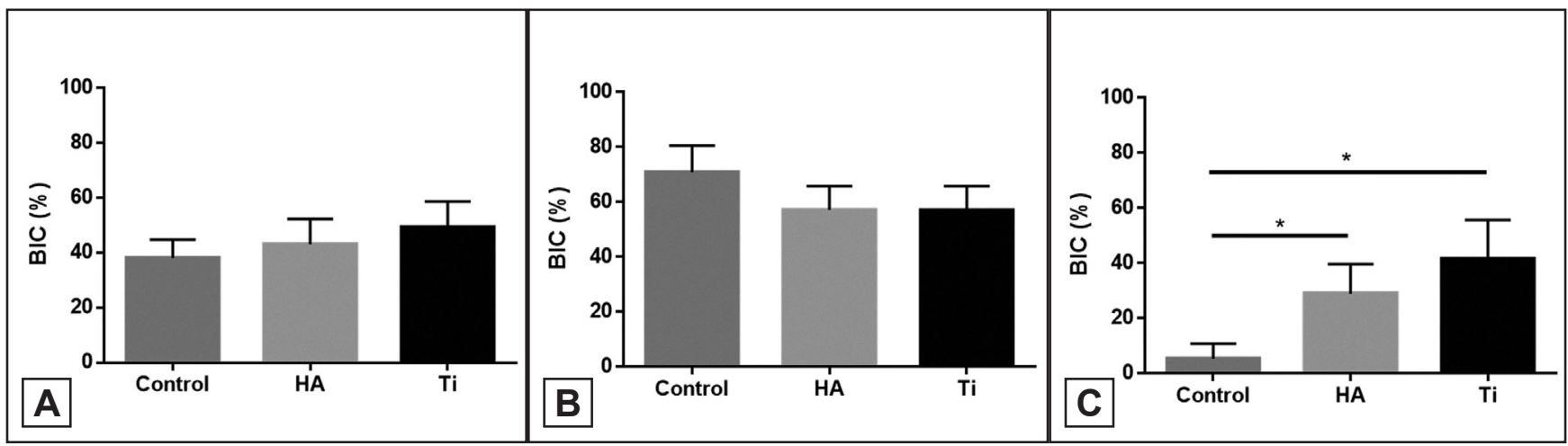

Figure 9. Bone-implant contact: $\mathrm{A}=$ whole area; $\mathrm{B}=$ cortical bone area; $\mathrm{C}=$ cancellous bone area.

There was no significant difference in the whole area $(\mathrm{P}=0.3$, Kruskal-Wallis test $)$ and cortical bone area $(\mathrm{P}=0.13, \mathrm{Kruskal}-$ Wallis test $)$. In the cancellous bone area, hydroxyapatite and titanium groups were higher than the control group.

$* \mathrm{P}<0.05$.

\section{DISCUSSION}

The present study shows that implants placed at sites reconstructed with porous $\mathrm{Ti}$ can achieve osseointegration. Both the porous Ti and porous HA possessed good osteoconduction properties due to an optimal pore size. Through SEM evaluation, the pores were found interconnected in both the samples, with the pore sizes being approximately 200 to $300 \mu \mathrm{m}$ in porous Ti and $150 \mu \mathrm{m}$ in porous HA. These pore sizes of 200 to $500 \mu \mathrm{m}$ are optimal for the colonization of osteoblasts and fibroblasts, or for vascularization within the biomaterial [14].

Failure of materials with low strength is seen when used to reconstruct large bone defects in/and loadbearing sites [15-17]. In our previous study [13], the porous $\mathrm{Ti}$ showed higher mechanical strength despite its increased porosity (85\%), compared to the porous $\mathrm{HA}$, and achieved adequate bone reconstruction at a critical-sized bone defect. In this study, we used hollow porous $\mathrm{Ti}$ as a bone reconstruction material. The inner hole was used for implant placement because it was not possible to prepare an implant bed in porous $\mathrm{Ti}$, which is harder than bone, using the normal drilling procedure; a high-speed drill is required. Eriksson et al. [18] reported that when the frictional heat during drilling exceeded $47{ }^{\circ} \mathrm{C}$, bone healing was impaired; therefore, low-speed drilling with irrigation is crucial. To overcome this limitation, we prepared the implant bed in the porous Ti samples before their placement at the bone reconstruction sites. De Santis et al. [19] reported that BIC was superior in bone sites reconstructed prior to implantation compared to when grafting and implantation were performed simultaneously. These results suggest that implant placement after preliminary bone reconstruction would give superior predictability at sites with large bone defects. The bone support around an implant body is essential for successful implant treatment. Bone support was assessed at the upper and lower portions alongside the implant. For BA and BIC, no significant differences were observed between the samples for the total BA. Reconstruction with porous Ti resulted in good implant osseointegration, similar to that with porous HA and at the pristine bone site. 
Moreover, BA and BIC values for porous Ti were not significantly different from the pristine bone site in the upper portion. The upper portion was surrounded by pristine bone tissue and is favourable for bone formation within both porous $\mathrm{Ti}$ and porous $\mathrm{HA}$. In our previous study, we showed that porous $\mathrm{Ti}$ and porous HA can achieve sufficient bone formation using a similar rabbit bone defect model. In contrast, the BA and BIC values in the lower portion were significantly higher for porous $\mathrm{Ti}$ and porous $\mathrm{HA}$ than for the pristine bone site. This may be attributed to the central part of the femur of a rabbit being primarily occupied by cancellous bone and bone marrow tissue [20].

These higher BA and BIC values in the lower portion suggest that porous biomaterials with excellent osteoconduction can achieve bone ingrowth from the surrounding pristine bone even in the cancellous $\mathrm{BA}$ and the bone marrow tissue. These results are consistent with that of our previous studies $[10,21]$ where bone formation was detected not only in the cortical bone portion of the porous HA but also inside the part that was located in the bone cancellous BA. Furthermore, we placed the implants in the pristine bone sites and reconstructed them using porous HA sites. The bone tissue surrounding the implant threads was then observed. As a result, the bone formation was not detected in the cancellous bone portion of the lower part of the pristine bone site; instead, the bone formation was detected in the cancellous bone portion inside the implant thread of the porous HA site and the bone tissue, which likely supports the placed implant. Based on these results, the BIC at the lower portion demonstrates increased bone formation with scaffolds such as porous Ti or porous HA. The results confirm the good osteoconduction ability of porous $\mathrm{Ti}$, similar to porous HA.

\section{CONCLUSIONS}

In this study, porous titanium achieved suitable osteoconduction for preliminary bone reconstruction before implant treatment, equivalent to that of porous hydroxyapatite, and implant support. To our knowledge, this is the first study to evaluate implant treatment after preliminary bone reconstruction using titanium biomaterial. Porous titanium is a suitable material for bone reconstruction before implant treatment in load-bearing situations that will allow for subsequent prosthetic treatments.

\section{ACKNOWLEDGMENTS AND DISCLOSURE STATEMENTS}

This study was supported by Scientific Research Grants (18K09683 and 19K19053) from the Japan Society for the Promotion of Science. The authors have no financial interest in any company or any of the products mentioned in this article.

\section{REFERENCES}

1. Branemark P-I. Introduction to osseointegration. In: Brånemark P-I, Zarb GA, Albrektsson T, editors. Tissue-Integrated Prostheses. Osseointegration in Clinical Dentistry. Chicago: Quintessence Publishing Co.; 1985. p. 11-43.

2. Wikesjö UM, Nilvéus R. Periodontal repair in dogs: effect of wound stabilization on healing. J Periodontol. 1990 Dec;61(12):719-24. [Medline: 2269912] [doi: 10.1902/jop.1990.61.12.719]

3. Schwarz F, Ferrari D, Balic E, Buser D, Becker J, Sager M. Lateral ridge augmentation using equine- and bovine-derived cancellous bone blocks: a feasibility study in dogs. Clin Oral Implants Res. 2010 Sep;21(9):904-12. [Medline: 20491835] [doi: 10.1111/j.1600-0501.2010.01951.x]

4. Burchardt H. The biology of bone graft repair. Clin Orthop Relat Res. 1983 Apr;(174):28-42. [Medline: 6339139] [doi: 10.1097/00003086-198304000-00005]

5. Reuben SS, Vieira P, Faruqi S, Verghis A, Kilaru PA, Maciolek H. Local administration of morphine for analgesia after iliac bone graft harvest. Anesthesiology. 2001 Aug;95(2):390-4. Retraction in: Anesthesiology. 2009 Mar;110(3):689. [Medline: 11506111] [doi: 10.1097/00000542-200108000-00021]

6. Tamai N, Myoui A, Tomita T, Nakase T, Tanaka J, Ochi T, Yoshikawa H. Novel hydroxyapatite ceramics with an interconnective porous structure exhibit superior osteoconduction in vivo. J Biomed Mater Res. 2002 Jan;59(1):110-7. [Medline: 11745543] [doi: 10.1002/jbm.1222]

7. Doi K, Kubo T, Hayashi K, Imura K, Akagawa Y. Development of cell-hybrid artificial bone: effect of osteogenic differentiation of bone marrow stromal stem cells on bone formation with newly developed interconnected porous calcium hydroxyapatite. Dent Mater J. 2007 Mar;26(2):162-9. [Medline: 17621930] [doi: 10.4012/dmj.26.162]

8. Shigeishi H, Takechi M, Nishimura M, Takamoto M, Minami M, Ohta K, Kamata N. Clinical evaluation of novel interconnected porous hydroxyapatite ceramics (IP-CHA) in a maxillary sinus floor augmentation procedure. Dent Mater J. 2012 Feb 3;31(1):54-60. [Medline: 22277606] [doi: $\underline{\text { 10.4012/dmj.2011-089] }}$ 
9. Doi K, Kubo T, Makihara Y, Oue H, Morita K, Oki Y, Kajihara S, Tsuga K. Osseointegration aspects of placed implant in bone reconstruction with newly developed block-type interconnected porous calcium hydroxyapatite. J Appl Oral Sci. 2016 Jul-Aug;24(4):325-31. [Medline: 27556202] [PMC free article: 4990360] [doi: 10.1590/1678-775720150597]

10. Makihara Y, Doi K, Oki Y, Kobatake R, Kubo T, Tsuga K. Stability of implants placed in bone reconstructed with blocktype interconnected porous hydroxyapatite. J Hard Tissue Biol. 2017 Oct;26(4):393-8. [doi: 10.2485/jhtb.26.393]

11. Feng YF, Wang L, Zhang Y, Li X, Ma ZS, Zou JW, Lei W, Zhang ZY. Effect of reactive oxygen species overproduction on osteogenesis of porous titanium implant in the present of diabetes mellitus. Biomaterials. 2013 Mar;34(9):2234-43. [Medline: 23294547] [doi: 10.1016/j.biomaterials.2012.12.023]

12. Hanawa T. Titanium-Tissue Interface Reaction and Its Control With Surface Treatment. Front Bioeng Biotechnol. 2019 Jul 17;7:170. [Medline: 31380361] [PMC free article: 6650641] [doi: 10.3389/fbioe.2019.00170]

13. Kobatake R, Doi K, Kubo T, Makihara Y, Oki Y, Yokoi M, Umehara H, Tsuga K. Novel fabrication of porous titanium by a resin-impregnated titanium substitution technique for bone reconstruction. RSC Adv. 2019 Jan;9(3):1625-31. [doi: $10.1039 /$ C8RA08744J]

14. Higashi T, Okamoto H. Influence of particle size of calcium phosphate ceramics as a capping agent on the formation of a hard tissue barrier in amputated dental pulp. J Endod. 1996 Jun;22(6):281-3. [Medline: 8934984] [doi: 10.1016/S0099-2399(96)80258-5]

15. Martz EO, Goel VK, Pope MH, Park JB. Materials and design of spinal implants--a review. J Biomed Mater Res. 1997 Fall;38(3):267-88. [Medline: 9283973] [doi: 10.1002/(SICI)1097-4636(199723)38:33.0.CO;2-8]

16. Ryan G, Pandit A, Apatsidis DP. Fabrication methods of porous metals for use in orthopaedic applications. Biomaterials. 2006 May;27(13):2651-70. [Medline: 16423390] [doi: 10.1016/j.biomaterials.2005.12.002]

17. Rezwan K, Chen QZ, Blaker JJ, Boccaccini AR. Biodegradable and bioactive porous polymer/inorganic composite scaffolds for bone tissue engineering. Biomaterials. 2006 Jun;27(18):3413-31. [Medline: 16504284] [doi: 10.1016/j.biomaterials.2006.01.039]

18. Eriksson AR, Albrektsson T. Temperature threshold levels for heat-induced bone tissue injury: a vital-microscopic study in the rabbit. J Prosthet Dent. 1983 Jul;50(1):101-7. doi: 10.1016/0022-3913(83)90174-9. [Medline: 6576145] [doi: 10.1016/0022-3913(83)90174-9]

19. De Santis E, Lang NP, Cesaretti G, Mainetti T, Beolchini M, Botticelli D. Healing outcomes at implants installed in sites augmented with particulate autologous bone and xenografts. An experimental study in dogs. Clin Oral Implants Res. 2013 Jan;24(1):77-86. [Medline: 22471739] [doi: 10.1111/j.1600-0501.2012.02456.x]

20. Minami M, Takechi M, Ohta K, Ohta A, Ninomiya Y, Takamoto M, Fukui A, Tada M, Kamata N. Bone formation and osseointegration with titanium implant using granular- and block-type porous hydroxyapatite ceramics (IP-CHA). Dent Mater J. 2013;32(5):753-60. [Medline: 24088830] [doi: 10.4012/dmj.2012-169]

21. Kubo T, Doi K, Hayashi K, Morita K, Matsuura A, Teixeira ER, Akagawa Y. Comparative evaluation of bone regeneration using spherical and irregularly shaped granules of interconnected porous hydroxylapatite. A beagle dog study. J Prosthodont Res. 2011 Apr;55(2):104-9. [Medline: 21300584] [doi: 10.1016/j.jpor.2010.10.001]

\section{To cite this article:}

Doi K, Kobatake R, Makihara Y, Oki Y, Umehara H, Kubo T, Tsuga K.

Osseointegration Aspects of Implants at the Bone Reconstruction Site by a Novel Porous Titanium Scaffold

J Oral Maxillofac Res 2021;12(3):e4

URL: http://www.ejomr.org/JOMR/archives/2021/3/e4/v12n3e4.pdf

doi: $10.5037 /$ jomr.2021.12304

Copyright $($ C Doi K, Kobatake R, Makihara Y, Oki Y, Umehara H, Kubo T, Tsuga K. Published in the JOURNAL OF ORAL \& MAXILLOFACIAL RESEARCH (http://www.ejomr.org), 30 September 2021.

This is an open-access article, first published in the JOURNAL OF ORAL \& MAXILLOFACIAL RESEARCH, distributed under the terms of the Creative Commons Attribution-Noncommercial-No Derivative Works 3.0 Unported License, which permits unrestricted non-commercial use, distribution, and reproduction in any medium, provided the original work and is properly cited. The copyright, license information and link to the original publication on (http://www.ejomr.org) must be included. 